Publicación semestral. ISSN 2215-4906

Volumen 79 - Número 1

Julio - Diciembre 2019

\title{
¿A qué jugamos?: Conlon, Harker y sus videos de Panamá
}

\author{
What's the Game?: Conlon, Harker \\ and their Videos of Panama
}

Mónica Kupfer

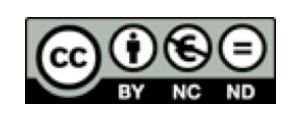

Esta obra está bajo una licencia Creative Commons Reconocimiento-No comercial-Sin Obra Derivada 


\title{
¿A qué jugamos?: Conlon, Harker y sus videos de Panamá
}

\author{
What's the Game?: Conlon, Harker \\ and their Videos of Panama
}

\author{
Mónica Kupfer ${ }^{1}$ \\ Fundación Arte \& Cultura \\ Panamá
}

Recibido: 13 de diciembre de 2017 Aprobado: 9 de octubre de 2018

\begin{abstract}
Resumen
Este ensayo analiza el trabajo colaborativo de los artistas Donna Conlon y Jonathan Harker. En los videos que producen juntos interpretan verdades sociopolíticas actuales del contexto panameño y el mundo globalizado, empleando un estilo lúdico y la estructura tradicional de los juegos, que vinculan sus obras con el concepto del arte como juego postulado por el filósofo Hans-Georg Gadamer. Conlon y Harker utilizan objets trouvées, elementos de la vida cotidiana, para crear juegos con los que confrontan asuntos de profunda importancia como la destrucción del ambiente y el patrimonio cultural de una nación, el desarrollo inmobiliario desmedido, las consecuencias sociales del consumismo y la corrupción, así como la complicada construcción de la supuesta identidad nacional. Juntos han creado un lenguaje artístico y un estilo divertido que involucran al espectador en los juegos y sus mensajes, de tal manera que la obra de arte se convierte en "una experiencia que modifica al que la experimenta".
\end{abstract}

Palabras clave: arte contemporáneo; Panamá; video; Conlon; Harker; Gadamer

1 Directora de la Fundación Arte \& Cultura, Panamá. Doctora en Arte Contemporáneo Latinoamericano por la Universidad de Texas, Austin, Estados Unidos. Correo electrónico: monica.kupfer@gmail.com 


\begin{abstract}
This essay analyzes the collaborative work of artists Donna Conlon and Jonathan Harker. In the videos they produce together, these artists interpret current sociopolitical reality, both in Panama and the globalized world, using a playful style and the traditional structure of games, which connect their work to the concepts espoused by philosopher Hans-Georg Gadamer regarding art as play. Conlon and Harker use objets trouvées, items from everyday life, to create games through which they confront matters of profound significance, such as the destruction of the environment and of a nation's cultural heritage, uncontrolled real estate development, the social consequences of consumerism and corruption, as well as the complicated construction of a supposed national identity. Together, they have created an artistic language and an entertaining style that involve their audience in the games and their messages, in such a way that the artwork becomes "an experience through which the spectator is transformed."
\end{abstract}

Keywords: contemporary art; Panama; video; Conlon; Harker 


\section{Ideas preliminares}

Durante más de una década, Donna Conlon y Jonathan Harker han colaborado en la producción de obras de videoarte. Emplean un estilo lúdico para crear narrativas de carácter poético y tono irónico enfocadas en las idiosincrasias del mundo actual y, más específicamente, de Panamá, donde ambos residen. Utilizan elementos de la vida cotidiana como "fichas" para juegos de su propia invención que hacen eco de situaciones sociopolíticas. Aunque es un tema que han estudiado diversos filósofos, es enriquecedor analizar el proceso creativo de Conlon y Harker con relación al concepto del arte como juego, postulado por el alemán Hans-Georg Gadamer, conocido, primordialmente, por sus escritos sobre la hermenéutica filosófica². Dos de sus publicaciones más importantes, Verdad y método (1973) y La actualidad de lo bello (1977), incluyen análisis sobre lo lúdico en el arte, con propuestas aplicables a la interpretación de los videos descritos en este ensayo.

Conlon y Harker usan objetos encontrados, a menudo, en la basura para confrontar temas relacionados con la naturaleza humana, las destructivas secuelas sociales y ecológicas del consumismo, y las consecuencias de la especulación inmobiliaria en Panamá. También, han explorado la falta de sentido histórico y la complicada construcción de la identidad nacional en ese pequeño istmo atravesado por un canal. Estas complejas circunstancias históricas y actuales Conlon y Harker las perciben, las aprovechan y a menudo las parodian en sus piezas. Aunque cada uno cuenta con una obra artística personal, la combinación de las personalidades de Conlon y Harker produce una alquimia particular. Esta ha desembocado en la creación de obras de arte que se basan en juegos semánticos, visuales, sonoros y artísticos en los que ellos participan como protagonistas, contrincantes y colaboradores. Juntos han creado un lenguaje artístico y un estilo divertido que conecta al público con el juego del arte, de tal manera que la experiencia estética y el mensaje de sus obras dejan su marca en el espectador.

\section{Trasfondo: cada cual, lo suyo}

Cuando se conocieron, en 2006, Conlon y Harker ya tenían carreras artísticas propias que, de hecho, han seguido desarrollando a la par de su obra conjunta. El encuentro

2 Entre los filósofos que han analizado la relación entre el juego y el arte, además de Gadamer, vale mencionar aquí a Kant, Schiller y Huizinga, aunque una consideración detallada sobrepasa los parámetros de este ensayo. Kant ubicó "la experiencia estética en ese juego libre que se da entre las facultades de la imaginación y del entendimiento...Schiller, quien identifica la plenitud de lo humano con el juego, centra su análisis en el diagnóstico crítico de la modernidad y en la reflexión sobre el potencial liberador del juego estético". Huizinga "defendió la tesis de que "el juego auténtico, puro, constituye un fundamento y factor de la cultura'” (García, 2011, pp.14-16). 
se dio en un momento en el que ambos exploraban el tema de la ciudad de Panamá. Era una época en que la urbe experimentaba un auge inmobiliario desproporcionado, con serias consecuencias ambientales y un trasfondo político preocupante. Con el tiempo, el descubrimiento de intereses compartidos los llevaría a una fructífera colaboración artística.

En el momento en el que Conlon, quien nació en los Estados Unidos, llegó a Panamá, en 1994, ya contaba con una maestría en Biología con un enfoque en Entomología. Posteriormente, hizo estudios de posgrado en Bellas artes, con especialización en Escultura, medio en el que trabajó por varios años. Luego, dio el paso a la fotografía, las intervenciones artísticas y los videos. Conlon practica el reciclaje como parte de su proceso creativo, producto de lo que ella define como "una búsqueda socio-arqueológica" para acumular objetos ordinarios e imágenes de su entorno usual, que luego usa "con el objetivo de revelar las idiosincrásicas del ser humano y las contradicciones inherentes en nuestro estilo de vida contemporáneo" (Conlon, s.f., párr.1). La proliferación de rascacielos en la ciudad de Panamá fue el tema de su video Espectros urbanos (2004) donde amontonó tapas de botellas y cajitas de fósforos para crear una pequeña urbe de desechos, que asemeja el perfil de la capital, al borde del mar. También exploró el tema del consumismo excesivo en sus videos Marea baja (2004) y Más me dan (2005). En el primero, cien llantas usadas de caucho (que nunca se degradará) ruedan y se acumulan al borde del mar. El segundo lo protagoniza un gran número de bolsas plásticas con logos comerciales, escondidas unas dentro de otras.

Esta bióloga-artista ha trabajado, en múltiples ocasiones, con elementos de la naturaleza, entre ellos, la jungla, las plantas y los insectos. En su video Refugio natural (2003), se observa cómo su mano "descubre" bichos que hacen sus vidas bajo desperdicios dejados por los seres humanos en el bosque. En la obra Coexistencia (2003), con la cual participó en la Bienal de Venecia de 2005, los insectos son los protagonistas de una narrativa en la que se intuye, pero no se ve la intervención humana. En este video, creado poco después de que Estados Unidos invadiera Iraq, Conlon filmó un insólito desfile de hormigas arrieras que cargan banderas de los países de las Naciones Unidas por el bosque lluvioso. Según Iria Candela, curadora del Museo Metropolitano de Nueva York, la visión de la naturaleza de Donna Conlon "no es simplista ni idealizada: lo natural, observado muchas veces a partir de su contacto o contraste con lo industrial, no solo se presenta como generación y vida, sino también como degradación y muerte" (Candela, 2012, p. 88). En este sentido, uno de los ejemplos más contundentes fue su Proyecto para mejorar la naturaleza (2007) en el cual Conlon utilizó alas, patas y antenas de insectos muertos para crear prototipos de bichos superdotados, pero inútiles.

Por otra parte, la trayectoria personal de Jonathan Harker se caracteriza por una inclinación hacia los temas urbanos, una sensibilidad analítica y un gusto por lo absurdo. 
Tiene, además, un notable conocimiento sobre sonido, ritmo y composición propio de su educación como cineasta (Araújo, 2006). Harker nació en Ecuador, pero vivió en Nueva York y Florida (E.E.U.U.) donde hizo sus estudios universitarios interdisciplinarios en Literatura, Filosofía, Bellas artes y Producción de video. Se mudó a Panamá en 1986. En su obra individual, Harker somete el ambiente urbano y el concepto de identidad nacional a burlas y subversiones. En sus intervenciones, se apropia de la ciudad capital de Panamá para producir "interesantes ejercicios audiovisuales con implicaciones urbanas y lúdicas, transitándola de una manera casi dadaísta y parodiando elementos sociales políticos y tradicionales" (Calvo \& Monge, 2009, p. 289). Su cortometraje El plomero (2002) se basa en una serie de relatos citadinos, donde un personaje se escapa de una de las anécdotas y camina por toda la ciudad. En 2002, su pieza ¿Cómo se llama la obra?, sobre el transporte urbano, fue el primer video premiado en la Bienal de Panamá. Ese mismo año presentó Panamá Postart, una serie de postales irónicas de Panamá en las que él aparece como protagonista en poses sugestivas y lugares insólitos que trastocan la usual publicidad turística y sus trillados eslóganes.

En Tomen distancia (2003), que se refiere al ritual performativo que llevan a cabo los estudiantes panameños cuando le cantan a la "patria", Harker filmó las vibraciones de su úvula mientras cantaba el himno nacional con una pequeña cámara en la boca. Se describe a sí mismo como un artista que busca "manipular y enfatizar las fronteras borrosas que existen entre lo inconográfico y lo ideológico, con la intención de retar, desestabilizar y alterar el espinoso sistema de percepciones, representaciones y valores que solemos llamar 'realidad'” (Trilnick, 2010, párr. 2). En 2007, participó en la Bienal de Venecia con el video Destablishing shots (2006), que ofrece un inventario tipológico de inmuebles de extrañas simetrías, en el espacio urbano panameño. Al año siguiente, pintó el mural conceptual Home go gringo sobre un muro en la antigua frontera con la Zona del Canal, como parte de la $8^{a}$ Bienal de Panamá. La obra de Harker es abiertamente contestaria, pues "cuestiona los juegos de poder y las identidades culturales forjadas en nuestra sociedad subdesarrollada y a la vez globalizada e hipercapitalista" (Samos, 2016, p. 138).

\section{A dúo: los primeros juegos}

La combinación de las personalidades de Conlon y Harker produjo un nuevo proceso estético y conceptual. Uno, en el que ellos logran potenciar el juego como una manera para crear obras de arte, a través de las cuales expresan verdades, a veces incómodas. El estilo basado en la interacción humana y la diversión en sus creaciones recuerda las ideas de Hans-Georg Gadamer, quien propuso el juego como el "modo de ser de la obra de arte" (Gadamer, 1993, p. 70) y declaró, además, que "lo que se representa en el juego del arte es lo permanentemente verdadero" (p. 76). En el análisis de la "secreta alianza existente entre arte y juego" que reconoce Gadamer, la investigadora española Paloma Martínez declara 
"en el juego del arte se juegan asuntos de vital importancia, pues justamente en su carácter lúdico yace la posibilidad de comprometer con la máxima seriedad aspectos fundamentales de nuestra realidad más inmediata" (Martínez, 2004, párr. 2). Los juegos de Conlon y Harker revelan ciertas características constantes: los jugadores son ellos mismos que, generalmente, figuran de manera anónima, representados por sus acciones o por alguna parte de sus cuerpos. No conversan, ni hay voz en off, pero los videos narran historias simbólicas a través de actividades que incorporan un sentido del humor, de competencia y de aparente libertad individual. Los videos tienden a seguir ritmos que aumentan o disminuyen en relación con las acciones de lo que asemeja un acto de esparcimiento, siempre acompañado por un cuidadoso manejo del sonido.

Este fue el caso desde su primer trabajo colaborativo, filmado en un área de reciclaje donde Conlon se interesó por unas grandes pilas de botellas desechadas con las que Harker empezó a jugar, lanzando y rompiendo los envases. Titulado Estación seca (2006), el video muestra una lluvia de botellas que vuelan por el aire para estrellarse contra una montaña de vidrio verde. La acción va en un crescendo de movimiento y sonido que asocia el reciclaje con un proceso de diversión, destrucción y catarsis.

De igual manera, percibimos un espíritu travieso en el partido que los artistas juegan en el video Tapitapultas (2012), título que combina "tapitas" con "catapultas": cruce entre lo divertido y lo bélico. Donde antes hubo una base militar (primero, norteamericana y luego, panameña) y hoy existe un parque natural, los artistas filmaron un juego en el que sus manos manipulan cucharas desechables para lanzar coloridos taponcitos plásticos. Los observadores participamos en el intercambio a través de lo que Gadamer llama "jugar-con", cuando describe el juego en el arte como "un hacer comunicativo en el sentido de que no conoce propiamente la distancia entre el que juega y el que mira el juego" (Gadamer, 1991, párr. 9). Al presentar la obra en este formato, Conlon y Harker involucran al espectador, al enfatizar su participación no solo en la acción de ese momento sino, también, en la interpretación de las acciones sociales y políticas que los artistas critican. Resulta claro que la meta de Tapitapultas es que las piezas caigan por el sumidero

Imagen 1. Detalle de Tapitapultas

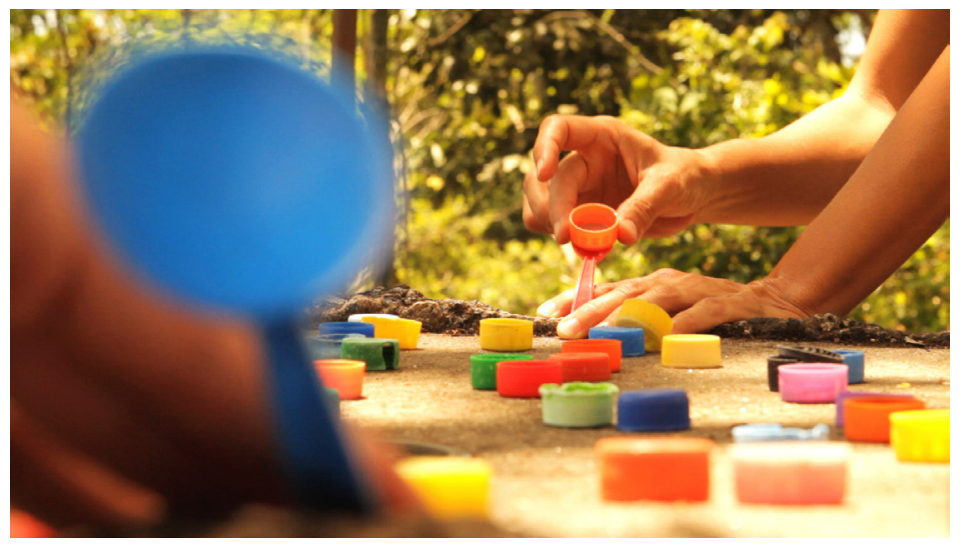

Fuente: Conlon y Harker (2013) 
de una plataforma abandonada. Debajo, forman una enorme montaña de plástico multicolor dentro del bosque, en lo que constituye un comentario sobre el "consumismo masivo, la contaminación y la desconexión que existe entre nuestras acciones y sus consecuencias" (Conlon \& Harker, 2012, párr. 1). Además, la intervención conlleva una carga histórica, pues alude a cómo los soldados usaron áreas de Zona del Canal para ensayar el arte de la guerra en simulaciones (o juegos) de batalla.

\section{Los (video) juegos}

La visión política de Conlon y Harker se volvió cada vez más explícita en sus videos posteriores a 2008. Justamente, cuando empezaron a producir su serie de Nideo) juegos, moviéndose, progresivamente, de los comentarios sobre la contaminación hacia una exploración de las ambigüedades históricas y los dramas políticos del país. En esta serie, la intencionalidad del juego como vehículo para la creación artística colaborativa alcanza su plenitud. (Video) juegos son protagonizados por las manos de los artistas, que participan en "juegos de mesa" irreconocibles que funcionan como símbolos y metáforas de situaciones reales. En (Video) juego 1 (2008) mueven pequeños ladrillos de manera, aparentemente aleatoria, que conduce a la formación de la palabra Panamá, en un lugar cuyo fondo resulta ser la vista de un gran buque comercial atravesando el Canal de Panamá. Según Harker: "the trick is finding those interstices, the crossroads between what is local and what is universal. And those are usually interesting fissure points, or volatile points, where you want to poke your finger in and see what happens [el truco está en encontrar esos intersticios, esos cruces entre lo que es local y lo que es universal. Y esas tienden a ser fisuras interesantes, puntos volátiles, donde uno quiere meter el dedo para ver qué pasa]" (Conlon \& Harker, 2014, 3:30-3:50 minutos).

La vía interoceánica es un elemento fundamental en los análisis de la situación, tanto histórica como reciente, del estado-nación panameño. En el (Video) juego 3 (2008), dos ladrillos desgastados deletrean "sí" o "no", dependiendo del movimiento de los jugadores. Siguiendo los criterios de Gadamer, nos encontramos ante un ejemplo de cómo, a través del juego, el arte apela al observador, quien participa en el vaivén entre aceptación y negación. Aunque permite amplias interpretaciones, desde los dilemas del subconsciente hasta las discusiones intrapersonales y los conflictos internacionales, la obra partió de una situación política específica: el referéndum nacional celebrado en octubre de 2006, para aprobar el proyecto de la ampliación del Canal de Panamá.

Las reacciones ante las transformaciones del paisaje y de los espacios urbanos panameños son elementos constantes en el trabajo de Conlon y Harker. En (Video) juego 2 (2008), los artistas manipulan azulejos rotos para conformar la silueta de una nueva ciudad 
de rascacielos, que recuerda obras anteriores de cada uno: Espectros urbanos (2004) de Conlon y Destablishing shots (2006) de Harker. Sin embargo, esta obra conjunta en donde un participante pone fichas y el otro las quita para colocar las suyas, va más allá. Tal como lo han descrito, para Conlon y Harker este juego hace eco de:

una metamorfosis esquizofrénica, que muchos consideran sintomática de la "modernización" [que] está arrasando la historia arquitectónica y la memoria colectiva de la ciudad. Hay un nivel de destrucción, casi antiséptico, de todos los antiguos edificios y casas, caracterizado por una absoluta despreocupación por sus valores estéticos, con el fin de poner en su lugar una ciudad "nueva", desalmada y vertical (Conlon \& Harker, 2010, p. 142).

En (Video) juego 5 (2009), dos formas metálicas fluctúan entre deletrear "we" y "me", un relajo semántico en el que una mano masculina reemplaza "nosotros" por "yo" (en inglés) y una mano femenina lo revierte a "nosotros" una y otra vez. Como observadores, también notamos el hecho de que un jugador tiene la piel más oscura que el otro ${ }^{3}$ : lo personal sigue siendo político. Como ha dicho la crítica Adrienne Samos: "son juegos... pero a la vez, son ingeniosas metáforas de juegos más peligrosos: identidades y contrariedades entre el in-

Imagen 2. Detalle de (Video) juego 4

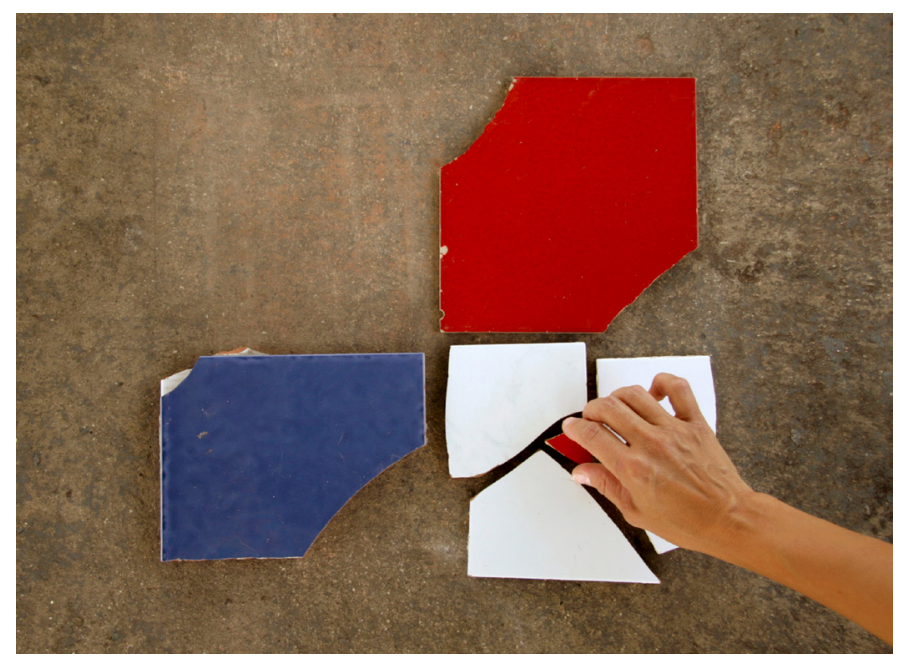

Fuente: Conlon y Harker (2009) dividuo, la pareja, la comunidad, y las fuerzas sociales y naturales" (Samos, 2016, p. 143).

Los juegos de Conlon y Harker exploran no solo la realidad visible de Panamá, también profundizan en el concepto de lo "patriótico". Específicamente, en el rol de los símbolos nacionales en la construcción de la identidad nacional. En (Video) juego 4 (2009), los artistas reubican fragmentos de mosaicos hasta conformar los cuatro rectángulos de la bandera panameña. Sin embargo, al final, en el cuadrante superior izquierdo, en lugar de una estrella, aparecen muchas,

${ }^{3}$ El tema de los roles que juegan el género y la diferencia racial en las obras de Conlon y Harker invita a un análisis que queda pendiente. Se trata de un aspecto de los videos que surge del proceso creativo y que, según los artistas, se dio de manera fortuita. 
como en la bandera norteamericana. Una ingeniosa referencia a la difícil relación que ha existido entre Panamá y los Estados Unidos. Esta circunstancia histórica se refleja, de manera aún más directa, en el video titulado Drinking Song (2011) que Conlon y Harker produjeron, específicamente, para la Bienal de Mercosur, que convocó a los artistas "a presentar, desde su propio imaginario y experiencia, alternativas a la idea convencional de nación en tiempos actuales" (Villasmil, 2011, párr. 1)

\section{Juegos de ritmos y sonidos}

Imagen 3. Detalle de Drinking Song

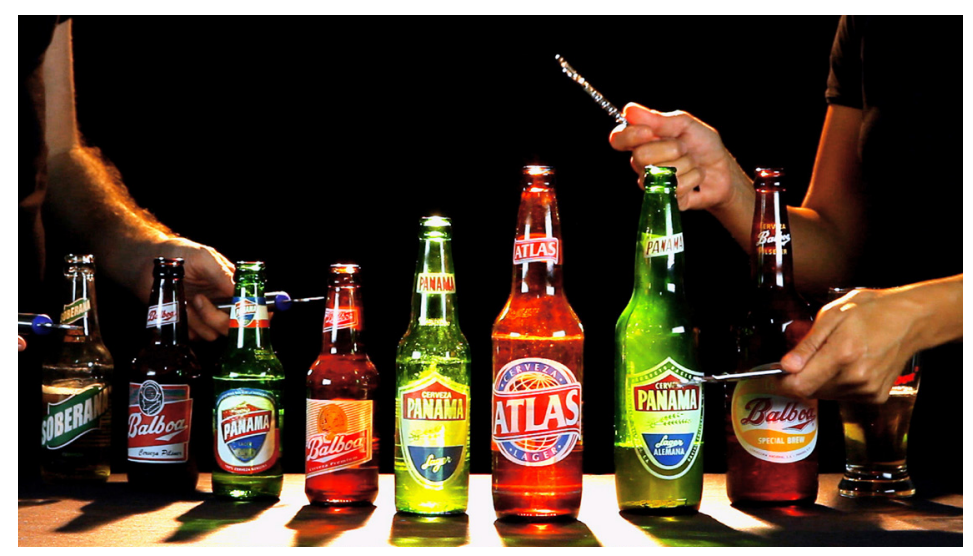

Fuente: Conlon y Harker
El título en inglés de Drinking Song no tiene una traducción exacta al español, pero, básicamente significa "canción para bebedores". En el video, los artistas (sus manos) tocan el himno nacional de los Estados Unidos repicando destapadores metálicos contra botellas de cerveza de conocidas marcas panameñas, colocadas en fila, como una especie de marimba vertical ${ }^{4}$. Los nombres de las cervezas reflejan ideas pseudo-patrióticas y aspiraciones políticas (Panamá y Soberana), así como leyendas históricas (Balboa). La más grande de las botellas es la de la cerveza Atlas, nombre que insinúa un vínculo entre el titán de la mitología griega y la manera en que Panamá conecta al mundo. El video evoca un anuncio de televisión, con una iluminación dramática y un familiar jingle, por una combinación de elementos vinculados a la situación colonial y poscolonial de Panamá. Como concluye la curadora Carmen Ferreyra, en su cuidadoso análisis de esta obra, Drinking Song hace "eco de la paradoja de la identidad panameña: mientras percibimos que las botellas (Panamá) son las encargadas de la organización del video, es la melodía (Estados Unidos) la que las une" (Ferreyra, 2011, párr. 20). Es revelador que el título deriva del hecho de que la melodía del himno nacional norteamericano tiene su origen en una tonada popular inglesa, una canción para la juerga.

4 Vale destacar que la palabra "jugar" en inglés es "play" que puede referirse tanto a participar en un juego como a tocar un instrumento o interpretar un papel en el teatro. En esta pieza, en particular, el juego es tanto musical como dramático. 
Conlon y Harker volvieron a conjugar un juego popular y una verdad histórica en el video Efecto dominó (2013), que filmaron en la parte colonial de Ciudad de Panamá (fundada en 1673 y considerada Patrimonio Mundial de la Organización de las Naciones Unidas para la Educación, la Ciencia y la Cultura [Unesco]). Debido al creciente interés inmobiliario por el llamado Casco Antiguo, el gobierno comisionó un proyecto -para muchos, absurdo- de levantar las calles coloniales con el fin de re-adoquinarlas con materiales nuevos. Para Conlon y Harker, aquellos antiguos adoquines (que, lamentablemente, serían destinados para rellenos en otras partes de la ciudad) representaron la incisiva materia prima para un nuevo juego. Para Efecto dominó, los artistas colocaron cientos de adoquines en posición vertical en una línea progresiva, que recorría todo el sector. En el video, vemos cómo el toque de un dedo da inicio a su caída progresiva, como una cadena de fichas de dominó. El sonido funciona en perfecta armonía con la imagen al reforzar la sensación de volumen de cada adoquín cuando cae y golpea al siguiente. La secuencia remite al conocido video de los artistas suizos Fischli y Weiss titulado Así van las cosas (1987) en el que una serie de objetos concatenados caen en secuencia. Sin embargo, Efecto dominó se diferencia en el sentido de que transmite un relevante comentario social: para sus creadores, estos adoquines humanizados representan una metáfora del supuesto desarrollo como una reacción en cadena.

Imagen 4. Detalle de Efecto dominó

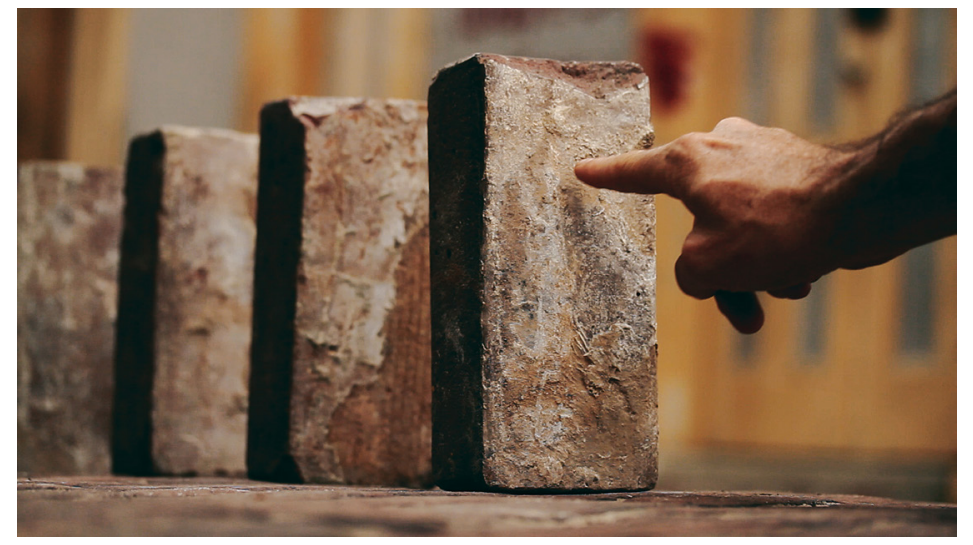

Fuente: Conlon y Harker (2013)

La habilidad que tienen Conlon y Harker para otorgarles carácter humano a entes inanimados resalta, especialmente, en el video Zincfonía tropical de 2013, en el que el juego asemeja una danza y los participantes son una gran cantidad de mangos. Son frutas preferidas entre los panameños, quienes los conocen no solo por su aroma y sabor, sino también por el sonido que hacen cuando los mangos maduros caen de los árboles sobre los techos. Conlon y Harker captan este sonido al inicio del video, donde vemos cómo, primero, un mango y, luego, muchos mangos caen y ruedan de manera estrepitosa por un paisaje abstracto de coloridas láminas de zinc, que evocan los techos típicos de las casas precarias en Panamá. Nuevamente, los artistas crean metáforas de situaciones humanas usando elementos de la cotidianeidad. En Zincfonía tropical, el primer mango aparece solitario (e incluso valiente) cuando llega al borde de un techo antes de caer al siguiente. Luego, sobrevive una invasión de mangos más "salvajes" y, hacia el final, se pierde entre la muchedumbre. 


\section{Juegos políticos y poéticos}

Si bien Zincfonía tropical ofreció la variable de un juego más liviano, en sus dos obras siguientes: Manos invisibles (2014) y Bajo la alfombra (2015), Conlon y Harker volvieron a los temas políticos. Además, hubo un cambio hacia representaciones más teatrales y hacia la creación de juegos escénicos. En este sentido, también se encuentran líneas paralelas con el pensamiento de Gadamer, para quien "también la representación dramática es un juego, es decir, tiene esa estructura del juego consistente en ser un mundo cerrado en sí mismo" (Gadamer, 1993, p.75). Las fichas en Manos invisibles son una enorme cantidad de monedas panameñas de un balboa (equivalente a un dólar) que fueron puestas en circulación en 2010, durante la presidencia de Ricardo Martinelli, las cuales fueron rechazadas por la mayoría de los panameños. Aunque el video utiliza los elementos de una divertida función de pantomima, en este caso, las manos con guantes blancos y los efectos teatrales sirven para reflejar una oscura realidad política y económica. Vemos cómo dos pares de manos, sin dueños, emergen de un espacio negro para contar, amontonar, repartir, intercambiar e, incluso, lavar la plata.

Imagen 5. Detalle de Zincfonía tropical

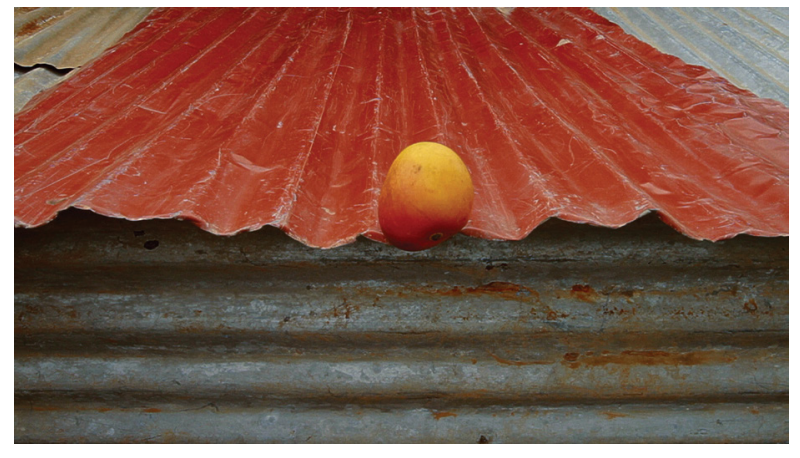

Fuente: Conlon y Harker (2013)
Imagen 6. Detalle de Manos invisibles

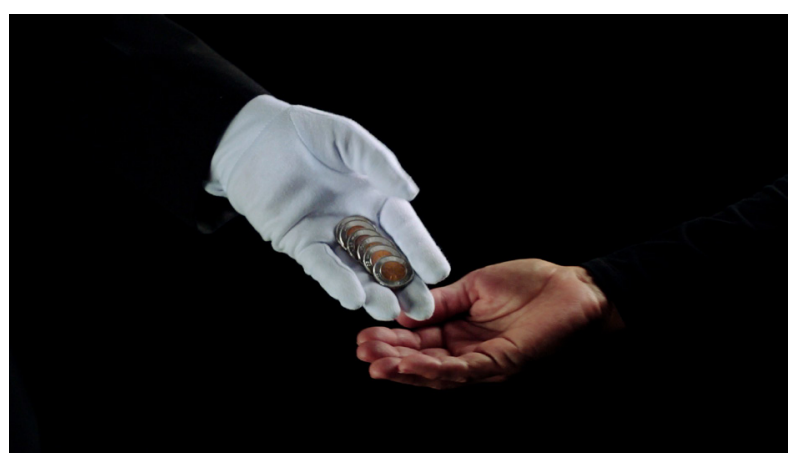

Fuente: Conlon y Harker (2010)

En Bajo la alfombra (2015) figuran Conlon y Harker como dos personas vestidas en overoles de personal de limpieza con patrióticos tonos de azul y rojo. Cargan un gran rollo de pasto verde sobre una delgada capa de tierra, que despliegan en el piso como una alfombra, debajo de la que proceden a barrer todo tipo de objetos desechados. Al final, los bultos subterráneos transforman la alfombra en una montaña que reproduce la forma del Cerro Ancón -punto geográfico emblemático en la lucha por la soberanía panameña-sobre el cual una mano planta la bandera nacional. Según los artistas: 
Todos hemos barrido cosas bajo la alfombra. Es tan fácil, tan conveniente: lo feo y lo sucio desaparece rápidamente bajo una superficie uniforme y prolija. Colectivamente, hacemos lo mismo, al esconder los episodios más nefastos de nuestras historias bajo mantos de silencio y olvido ... Rubén Blades canta "prohibido olvidar", pero el himno nacional de Panamá lo contradice de lleno, proclamando imperiosamente que "es preciso cubrir con un velo el pasado, el calvario y la cruz" (Bienal Centroamericana, 2016, párr. 4).

Imagen 6. Detalle de Bajo la alfombra

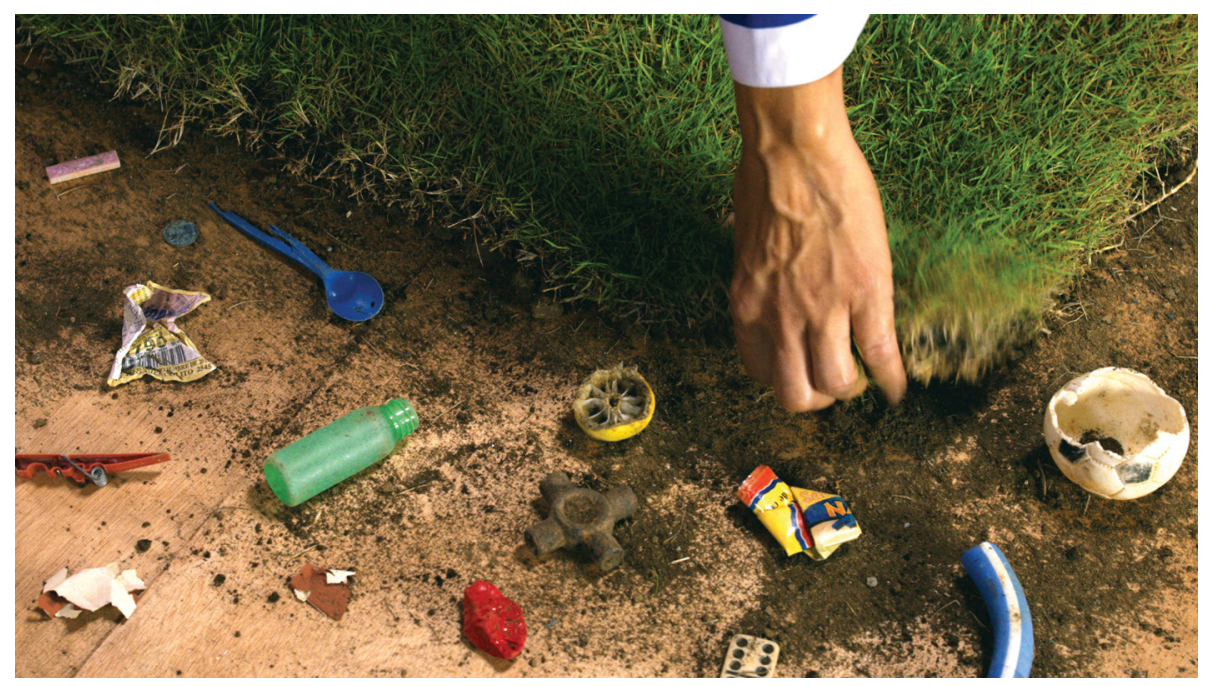

Fuente: Conlon y Harker (2015)

La tendencia hacia lo teatral culminó dos años después, con la creación del video Lotería (2017) que, además, muestra un estilo cinematográfico más sofisticado, cargado de drama y poesía ${ }^{5}$. Conlon y Harker filmaron Lotería en blanco y negro, intencionalmente, y emplean un lenguaje visual vinculado al cine experimental de la década de 1940. El video traspasa la línea de lo real a lo onírico en seis historias ligadas a las emblemáticas balotas blancas de la suerte. Estas resultan alegorías de lo fortuito que se transmutan en otros objetos esféricos como perlas, píldoras, frutas o huevos de tortuga escondidos en la arena.

${ }^{5}$ Es significativo que, para el proceso técnico y creativo de esta obra, Conlon y Harker contaron con un equipo de colaboradores. En Lotería participaron Ana Endara como directora, Víctor Mares como director de fotografía, e Iñaki Iriberri en el diseño del sonido, el cual fue creado con un sintetizador análogo. 
Lotería presenta un mundo de sueños cargado de sensaciones, sombras, incertidumbres y situaciones tenebrosas. Según los artistas conectan "las propiedades icónicas y formales de las esferas enigmáticas dentro de un vaivén meta-narrativo que sugiere que la existencia es una constante e impredecible apuesta entre la vida y la muerte" (Conlon \& Harker, 2017a, párr. 1) En el video, nos encontramos con juegos de luces y sombras; de las olas del mar; movimientos o vaivenes de los participantes en la acción; y de los personajes desconocidos que transmiten una sensación de incertidumbre.

El movimiento constituye un elemento esencial en Voz a la deriva (2017), el más reciente video de Conlon y Harker, donde una botella de plástico transporta un mensaje susurrado. El envase parece bailar llevado por la corriente de una lluvia tropical, en un paisaje urbano. Según los artistas, la obra "cuenta una historia de alienación y comunión, angustia y esperanza, fragilidad y resiliencia humana ante un mundo en crisis, tanto política como social y ambiental" (Conlon y Harker, 2017b, párr. 1). Aunque, aquí, no son sus manos las que toman parte del partido, sigue presente la idea del juego en el mensaje secreto que contiene la botella, en la danza del envase, el teatro cotidiano de la contaminación y el movimiento de las aguas. Conlon y Harker siguen jugando.

\section{Conclusión}

En su primer video colaborativo, Conlon y Harker empezaron con el juego de lanzar botellas desde la posición que ocupaban fuera del cuadro fílmico. Luego, se incorporaron a la acción, por medio de sus manos y brazos, como participantes en juegos de tablero. Finalmente, en años recientes, figuraron como actores de cuerpo entero en piezas más cercanas a una puesta en escena teatral o filmográfica. Aunque su presencia en los videos es esencial, ellos permanecen siempre como actores anónimos, de tal manera que el espectador se concentra en el juego, en la realidad que representa o en su interpretación metafórica, lo que constituye el meollo de sus obras. Según Gadamer, es solo en el juego que el arte "alcanza su pleno significado. Los actores representan su papel como en cualquier juego y el juego accede así a la representación; pero el juego mismo es el conjunto de actores y espectadores" (Gadamer 1993, p. 75). Como observadores nos convertimos en parte del "juego-con" que proponen los artistas. Percibimos los movimientos y participamos en la acción.

A través de los juegos y las actuaciones en sus videos, Conlon y Harker confrontan temas de profundo significado para el contexto de Panamá y del mundo globalizado. Son creativos en sus métodos y meticulosos en su técnica, para involucrarnos en una actividad lúdica que -de manera engañosamente divertida y a través de fichas que no son más que objets trouvées- trae a consciencia duras verdades sobre la realidad actual, el ser humano, los daños que producen el consumismo y la especulación. A la vez, abordan temas como el descuido del planeta, la corrupción política y las falsas construcciones de identidad. Así: 
la obra de arte tiene su verdadero ser en el hecho de que se convierte en una experiencia que modifica al que la experimenta. El "sujeto" de la experiencia del arte, lo que permanece y queda constante, no es la subjetividad del que lo experimenta sino la obra de arte misma. Y este es precisamente el punto en el que se vuelve significativo el modo de ser del juego (Gadamer 1993, p. 145).

Conlon y Harker aparecen en sus videos, pero, también desaparecen, en el sentido de que no los identificamos como individuos, ni se dan ellos un lugar en el que cuente su presencia subjetiva. Más bien, funcionan como instrumentos de juegos creados para transformarnos. Juntos han creado un lenguaje artístico y un estilo divertido que involucra al espectador en sus juegos y mensajes. Logran que la obra de arte se convierta en "una experiencia que modifica al que la experimenta".

\section{Referencias}

Araújo, W. (2006). Donna Conlon y Jonathan Harker. Estrecho Dudoso. Costa Rica: Teorética.

Bienal Centroamericana (2016). Donna Conlon y Jonathan Harker. Bienal Centroamericana [página web]. Recuperado de http://www.bienalcentroamericana. com/2016/08/04/donna-conlon-jonathan-harker/

Calvo, E. \& Monge, M.J. (2009). New Technologies in Central American Contemporary Art: A Partial Archaeology and Some Critical Appreciations from the Institutional Real. Third Text, 3(23), 281-292.

Candela, I. (2012). Contraposiciones: Arte contemporáneo en Latinoamérica, 19902010. Madrid: Alianza Editorial.

Conlon, D. (s.f.). Declaración. Sitio web de Donna Conlon [página web]. Recuperado de http:// www.donnaconlon.com/?page_id=40\&lang=es

Conlon, D. \& Harker, J. (2010). Donna Colon, Jonathan Harker. En Olmo, S. (editor) XXXI Bienal de Pontevedra - Utrópicos. Recuperado de https://issuu.com/mauricioesquivel/docs/ utropicos_vol.i_roteiro_-_guia_-_gu

Conlon, D. \& Harker, J. (2012). Capapults [Tapitapultas]. En Conlon and Harker videos. [página web].Recuperado de https://vimeo.com/89960581

Conlon, D. \& Harker, J. (2014). Conlon and Harker: A Playful Collaboration. Guggenheim Museum [entrevista en página web]. Recuperado de https://www.guggenheim.org/map-artist/donna-conlon-and-jonathan-harker 
Conlon, D. \& Harker, J. (2017a). Lottery [Lotería]. En Conlon and Harker videos [página web]. Recuperado de: https://vimeo.com/200040594

Conlon, D. \& Harker, J. (2017b). The Voice Adrift [Voz a la deriva]. En Conlon and Harker videos [página web]. Recuperado de https://vimeo.com/242328876

Ferreyra, C. (2011). Imágenes y sonido en Drinking Song, por Donna Conlon y Jonathan Harker. Sauna, Revista de Arte Año 3(25). Recuperado de http://www.revistasauna.com. ar/03-25/10.html

Gadamer, H-G. (1991). El elemento lúdico del arte. En La actualidad de lo bello. El arte como juego, símbolo y fiesta (pp. 66-83). Recuperado de http://www.revistadeartes.com.ar/revistadeartes_8/el-elemento-ludico-del-arte.html

Gadamer, H-G. (1993). El juego como hilo conductor de la explicación ontológica. En Verdad y Método (pp. 143-181). Salamanca: Sígueme.

García, B. (2011). La teoría estética del juego. De Schiller a nuestros días. Madrid: Universidad Autónoma de Madrid, Universidad Complutense de Madrid y Museo Nacional Centro de Arte Reina Sofía. Recuperado de https://bit.ly/2I9Lvai

Martínez, P. (julio-septiembre, 2004). ¿Qué se juega en el arte? Revista Teína, 05. Recuperado de http://www.revistateina.es/teina/web/teina5/dos4.htm

Samos, A. (2016). P(l)ayback: el videoarte como medio contestatario en Panamá. En Divorcio a la panameña. Saltos y rupturas en el arte de Panamá: 1990-2015. Costa Rica: Teorética.

Trilnick, C. (1 de mayo de 2010). Jonathan Harker. Proyecto IDIS [página web]. Recuperado de https://proyectoidis.org/jonathan-harker/

Villasmil, A. (2011). Una bienal integral, que no es apenas una gran exposición. Artishock, revista de arte contemporáneo. Recuperado de http://artishockrevista.com/2011/09/13/ una-bienal-integral-no-apenas-una-gran-exposicion/ 